\title{
The Effects of Stereotactic Cerebroventricular Administration of Albumin, Mannitol, Hypertonic Sodium Chloride, Glycerin and Dextran in Rats with Experimental Brain Edema
}

\author{
Tuncay ATES ${ }^{1}$, Yurdal GEZERCAN², Guner MENEKSE ${ }^{3}$, Yusuf TURKOZ ${ }^{4}$, Hakan PARLAKPINAR ${ }^{5}$, \\ Ali Ihsan OKTEN ${ }^{2}$, Yener AKYUVA ${ }^{6}$, Selami Cagatay ONAL ${ }^{6}$ \\ ${ }^{1}$ Cukurova Dr. Askim Tufekci State Hospital, Department of Neurosurgery, Adana, Turkey \\ ${ }^{2}$ Numune Training and Research Hospital, Department of Neurosurgery, Adana, Turkey \\ ${ }^{3}$ Ankara Training and Research Hospital, Department of Neurosurgery, Ankara, Turkey \\ ${ }^{4}$ Inonu University, Faculty of Medicine, Department of Biochemistry, Malatya, Turkey \\ ${ }^{5}$ Inonu University, Faculty of Medicine, Department of Pharmacology, Malatya, Turkey \\ ${ }^{6}$ Inonu University, Faculty of Medicine, Department of Neurosurgery, Malatya, Turkey
}

\section{ABSTRACT}

AIM: To evaluate the effects of cerebroventricular administration of hyperoncotic/hyperosmotic agents on edematous brain tissue in rats with experimental head trauma.

MATERIAL and METHODS: The study included 54 female Sprague-Dawley rats with weights ranging between 200 and $250 \mathrm{~g}$. Six experimental groups were examined with each group containing 9 rats. All rats were exposed to head trauma, and treatment groups were administered $2 \mu \mathrm{l}$ of one of the drugs (albumin, mannitol, hypertonic sodium chloride ( $\mathrm{NaCl}$ ), glycerin and dextran) 6,12 and 24 hours after the trauma via the cerebroventricular route and using a stereotactic device. Rats were sacrificed 48 hours after the trauma, and brain tissues were extracted without damage. Biochemical analyses including reduced glutathione (GSH), nitric oxide (NO), malondialdehyde (MDA), tumor necrosis factor alpha (TNF-a), and interleukin 1 beta (IL-1 $\beta$ ) were performed on the injured left hemisphere.

RESULTS: Compared with the control group, the albumin, mannitol, $3 \% \mathrm{NaCl}$ and glycerin treatment groups revealed dramatic increases in GSH levels $(p<0.001)$. Levels of MDA, which is the end-product of brain edema and lipid peroxidation, failed to show a statistically significant decrease, but there was a decreasing trend observed in the inter-group comparisons. NO levels were also decreased in the $3 \% \mathrm{NaCl}$ treatment group. An analysis of TNF-a and IL-1 $\beta$, two proinflammatory cytokines associated with the trauma, revealed that IL-1 $\beta$ decreased significantly in all treatment groups $(p=0.001)$, whereas no significant difference was detected in TNF-a levels.

CONCLUSION: Cerebroventricular administration of hyperoncotic/hyperosmotic agents provides substantial effects on the treatment of brain edema.

KEYWORDS: Albumin, Brain edema, Cerebroventricular administration, Dextran, Glycerin, Head trauma, Mannitol, $\mathrm{NaCl}$ 


\section{INTRODUCTION}

$\mathrm{T}$ Iraumatic brain injury is a serious public health problem worldwide. The treatment and management of brain edema, especially after head trauma, is a major problem for clinicians. Therefore, researchers have aimed to improve our understanding of the treatment and mechanisms involved in brain edema $(19,42)$.

Acute brain damage leads to primary and secondary injury in neural tissue. The leading mechanisms involved in the secondary injury are the release of superoxide radicals, hydrogen peroxide $\left(\mathrm{H}_{2} \mathrm{O}_{2}\right)$, abnormal formation of free oxygen radicals, excessive amounts of excitatory amino acids, and nitrous oxide (NO), which is an inflammatory mediator (7).

Brain edema can be defined as an increase in the water content in the intra- or intercellular spaces. This process begins with the definition of vasogenic edema provided by Klatzo (23), which is based on classical experiments. A volumetric increase in water can result from an increase in blood flow or tissue fluids, depending on the pathophysiological conditions (10). Increased intracranial pressure produced by vascular brain injury is mediated by an increase in cerebral water content or blood flow $(3,17,18)$. Vascular permeability, changes in vasomotor function and the dynamics involved in brain edema must be understood to eliminate increases in intracranial pressure due to edema $(10,13,17)$.

Treatment of brain edema secondary to head trauma is one of the most important problems waiting to be solved by neurosurgeons. Experimental studies examining the treatment of brain edema have typically used hyperoncotic and hyperosmotic agents. The effects of these agents were investigated in experiments that involved intravenous administrations in ischemic and traumatic brain edema $(5,25,27)$. The bloodbrain barrier must be intact for the effective treatment of brain edema by these agents $(4,17,21)$. When both the positive and negative aspects of anti-edema therapies are considered, one can conclude that substantial research is required to attain a fully effective treatment $(10,13)$.

In the present study, we compared the effects of cerebroventricular administration of hyperoncotic/hyperosmotic agents, such as albumin, mannitol, hypertonic $\mathrm{NaCl}$, glycerin and dextran, on edematous brain tissue in rats with experimental head trauma.

\section{- MATERIAL and METHODS}

This study was approved by the Inonu University, Experimental Research Unit and Experimental Animal Ethics Committee on 15.03.2010 with research protocol number of 2010/22 and was conducted between May 2010 and August 2010.

Fifty-four adult female Sprague-Dawley rats weighing 200$250 \mathrm{~g}$ were used in the experiments. The study was performed using surgical instruments, a stereotactic apparatus and a device that used weights to induce head trauma.

\section{Trauma Model}

All rats received via intraperitoneal administration $10 \mathrm{mg} / \mathrm{kg}$ of xylazine (Bayer Birlesik Alman llac Fabrikalari, Istanbul) and 75 $\mathrm{mg} / \mathrm{kg}$ of ketamine hydrochloride (Parke Davis, Istanbul) prior to surgery. Doses that did not exceed $20 \%$ of baseline doses were repeated intermittently and as needed.

Moderate head trauma was induced using Feeney's weightdrop technique (11). A 10x15 mm craniectomy was performed to the left of the midline and included the parietal adjacency of temporal bone. The dura was left intact. Then, the rats were head-traumatized using Feeney's device with a force of $450 \mathrm{~g} /$ $\mathrm{cm}$. Following the head trauma, the skin was closed over the craniectomy as a single layer. The operations were performed in compliance with aseptic principles.

Head-traumatized rats in the treatment group were administered a cerebroventricular drug following anesthesia at 6,12 and 24 hours after trauma using rat stereotaxic device (ASI instruments small animal stereotaxic frame, Istanbul). Rats were placed in the stereotaxic device with the incisor bar elevated 5 $\mathrm{mm}$ above the interaural line. Therapeutic agents were administered by the cerebroventricular route, each with a dose of 2 $\mu \mathrm{l}$, at 6,12 and 24 hours after trauma. The agents were administered via a Hamilton syringe (No. 24) mounted on the stereotaxic device (Figure 1) that targeted the left lateral ventricle using the coordinates reported in the Pellegrino-Cushman (35) atlas. The skin was closed as a single layer after the treatment. All animal subjects were released for food and fluid requirements after the procedures.

\section{Experimental Groups}

Rats were randomly assigned to six groups with equal numbers in each group (Table I). There were 9 rats in each group until the time of sacrifice.

The treatment groups including the following: the first group (albumin), second group (mannitol), third group (3\% sodium chloride), fourth group (glycerin) and fifth group (Dextran). The rats in the trauma treatment group were administered $1 \mathrm{ml}$ of physiological saline solution by the intraperitoneal route after head trauma, and they were given $2 \mu$ of albumin, mannitol, $3 \%$ sodium chloride, glycerin, or dextran by the cerebroventricular route, at 6,12 and 24 hours using the stereotaxic device. Rats in the sixth group, which was the non-treated trauma group, served as controls and received intraperitoneal injection of $1 \mathrm{ml}$ physiological saline solution following anesthesia after head trauma. Rats were placed in the stereotactic device and punctured with the syringe, without injecting a therapeutic agent at 6, 12 and 24 hours. A total of 9 rats in each group were sacrificed for biochemical analysis 48 hours following trauma.

\section{Perfusion and Tissue Sampling}

For all groups, rats were deeply anesthetized with xylazine and ketamine after a pre-determined period of time and then thoracotomized. Following the thoracotomy, intracardiac perfusion was performed with physiological saline for 5 minutes. Immediately after perfusion, the brain tissue was carefully removed without damaging the tissue. Tissue samples were taken from the traumatized hemisphere at the epicenter and periphery of the injury and from the contralateral 
Table I: Group Numbers and the Number of Rats Sacrificed 48 Hours After Trauma

\begin{tabular}{ll}
\hline Groups & Number of living rats \\
\hline $1^{\text {st }}$ group (Albumin) & 8 \\
\hline $2^{\text {nd }}$ group (Mannitol) & 9 \\
\hline $3^{\text {rd }}$ group (3\% sodium chloride) & 7 \\
\hline $4^{\text {th }}$ group (Glycerin) & 7 \\
\hline $5^{\text {th }}$ group (Dextran) & 7 \\
\hline $6^{\text {th }}$ group (Non-treated trauma group) & 6 \\
\hline
\end{tabular}

hemisphere. Tissue samples were placed in pre-prepared dishes that were numbered for each subject and were stored at $-70^{\circ} \mathrm{C}$ for biochemical analysis.

\section{Preparation of Tissue Samples for Biochemical Analysis}

Brain samples from each group were weighted and homogenized (Ultra Turrax Type T25-B homogenizer, IKA Labortechnic, Germany) with phosphate buffer ( $\mathrm{pH}: 7.4,50 \mathrm{mM})$ on ice at $12000 \mathrm{rpm}$ for $1-2$ minutes to form $10 \%$ (w/v) homogenate. Some of these homogenates were used in the MDA analysis, and the remaining homogenates were centrifuged at $500 \mathrm{rpm}$ for 30 minutes at $4^{\circ} \mathrm{C}$. The supernatant samples were used in the IL-1 $\beta$, TNF-a, GSH and NO analyses. IL-1 $\beta$ and TNF- $a$ rat Platinum ELISA kits (Platinum ELISA eBioscience, North America) were used in the cytokine analysis.

\section{Statistical Analyses}

Statistical analyses were performed using the SPSS 15.0 program, and the data are presented as the median (min-max). Because a normal distribution was not assumed, the KruskalWallis $\mathrm{H}$ test was used to compare the medians between groups. A Mann-Whitney $U$ test with the Bonferroni correction was used to perform multiple comparisons. $\mathrm{P}<0.05$ was considered significant. Graphs were created using Microsoft Excel.

\section{RESULTS}

In the traumatic brain injury (TBI)-induced rats, NO levels were decreased, especially in the $\mathrm{NaCl} 3 \%$-treated group (Group 3) (Figure 2).

The groups treated with albumin, mannitol, $3 \% \mathrm{NaCl}$ or glycerin (Groups 1, 2, 3, and 4, respectively) showed significant increases in GSH levels. However, the dextran-treated group (Group 5) failed to show an increase (Figure 3).

The MDA analysis revealed decreased levels in the albumin, mannitol, $3 \% \mathrm{NaCl}$ and glycerin treatment groups (Group $1,2,3,4)$ compared with the control group (Figure 4).

Levels of TNF- $a$ and IL-1 $\beta$, two pro-inflammatory cytokines associated with TBI, were measured in the brain tissue. IL-1 $\beta$ levels were substantially increased in the non-treated trauma group but not in the treatment groups (Groups 1,2,3,4, and 5) (Figure 5) $(p=0.001)$.
There were no statistically significant differences in TNF-a levels measured in the brain tissue (Figure 6) $(p=0.06)$.

\section{DISCUSSION}

Previous studies performed in models of TBI have

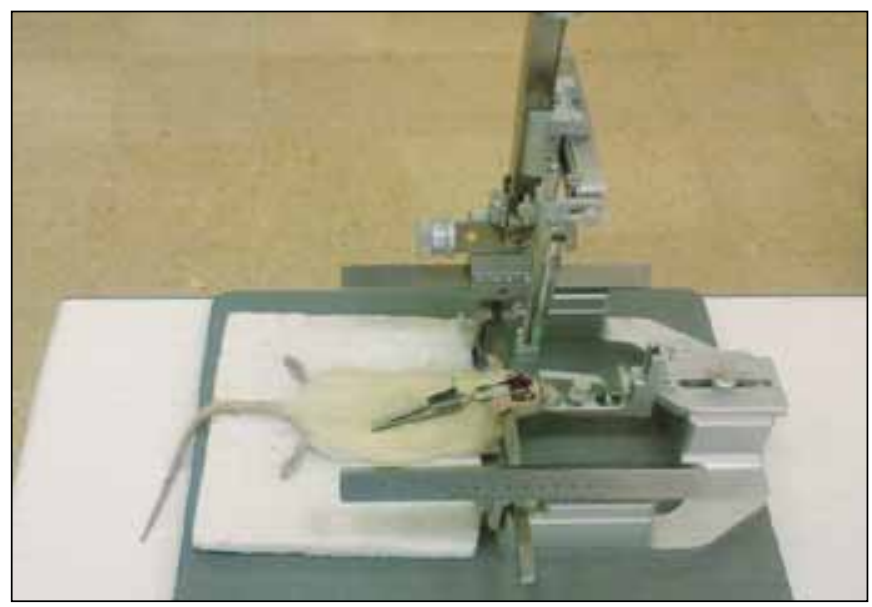

Figure 1: Rat placed in stereotaxic device.

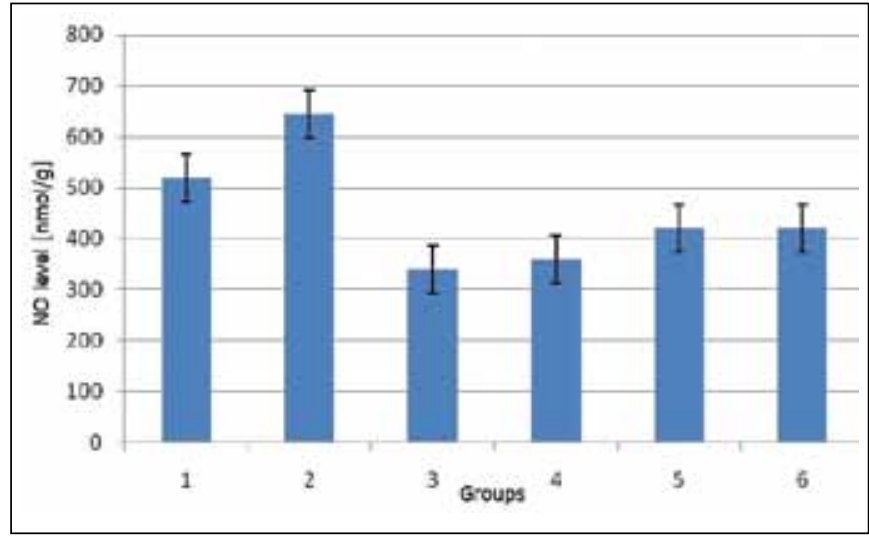

Figure 2: Distribution of NO level measured in brain tissue according to group.

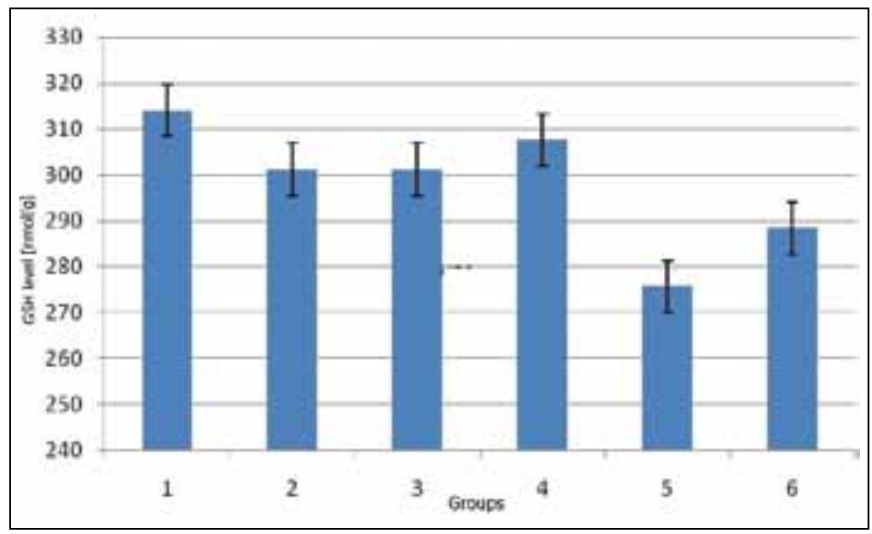

Figure 3: Distribution of GSH level measured in brain tissue according to group. 
demonstrated that edema develops within 3 hours of the injury, peaks between 48 and 72 hours and decreases considerably in the following 7-10 days. Clinical experience supports the findings of these previous studies $(1,29,33)$.

Brain edema that develops shortly after head trauma and progresses rapidly triggers several pathological processes

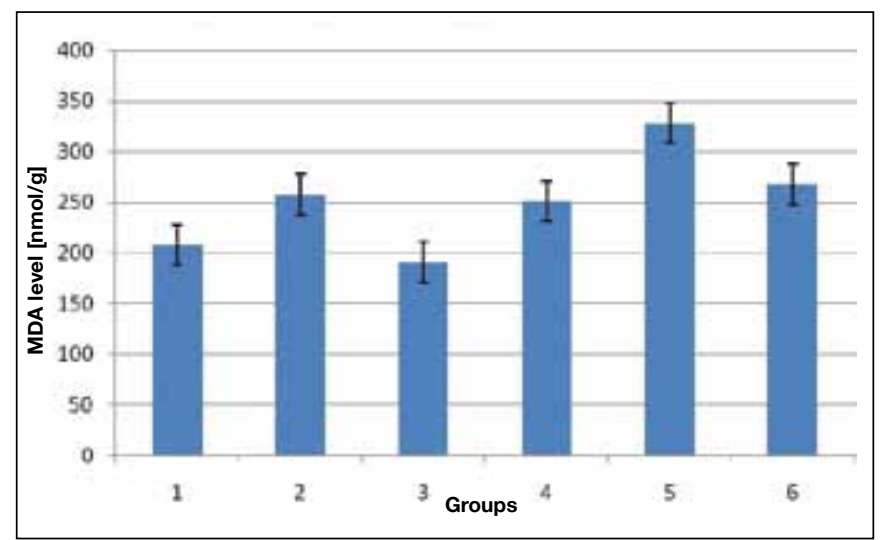

Figure 4: Distribution of MDA level measured in brain tissue according to group.

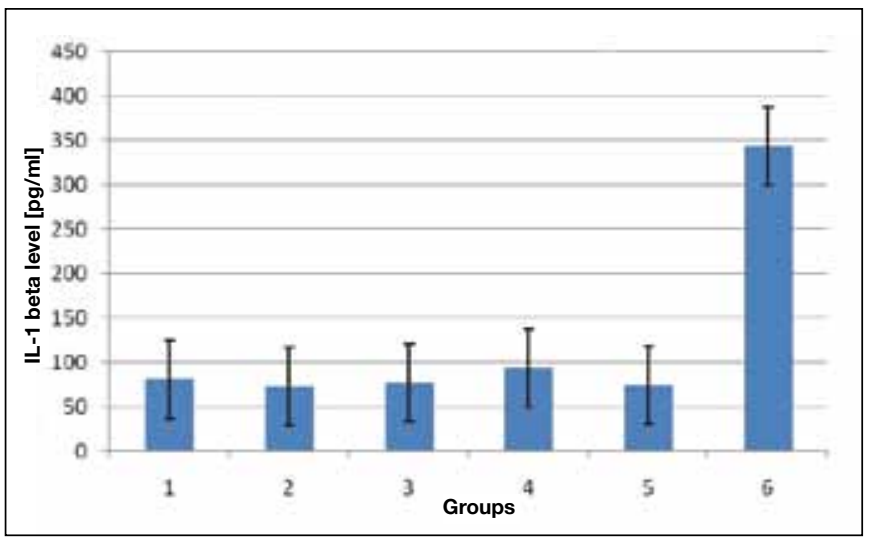

Figure 5: Distribution of IL-1ß level measured in brain tissue according to group.

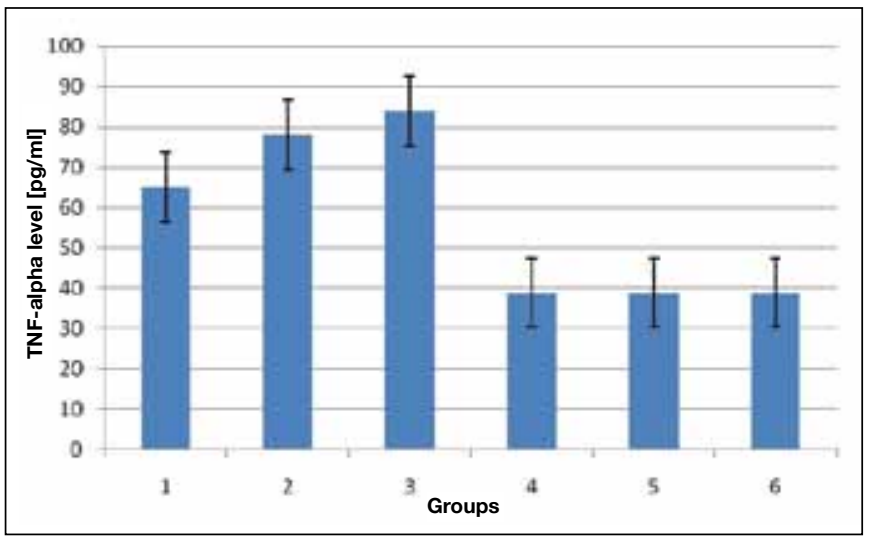

Figure 6: Distribution of TNF-a level measured in brain tissue according to group.
(30). Of these processes, one of the most important is constriction of vascular structures resulting in an increased intracranial pressure, which leads to hypo-oxygenation and ultimately anoxia (29).

An advantage of drug treatments delivered by the intracisternal, intrathecal or intraventricular routes is that the drug does not need to cross the blood-brain barrier, which is a concern with other treatment options (30). Although the integrity of the blood-brain barrier can be compromised in head trauma and this facilitates drug treatments in reaching neural tissue, most treatment efforts aim to temporarily open the tight junctions of brain endothelial cells with agents such as arabinose or mannitol (14).

Many reports describe the free radical scavenging and strong antioxidant effects of mannitol. A study by Stratford (41) that examined the antioxidant effects of intravenous fluids suggested that mannitol had no antioxidant effects. This was explained by an increase in oxidative stress due to an abundant and active radical produced by the reactive oxygen consumption of mannitol.

To date, studies focusing on the administration of the hypertonic saline dextran solution (DS) have been limited to studies related to recovery from hemorrhagic shock. However, these agents were confirmed to decrease intracranial pressure in experiments performed in animals with head trauma (28).

Berger et al. (4) compared hypertonic DS with hypertonic mannitol and their ability to reduce intracranial hypertension from a focal cerebral lesion and intracranial mass, and they reported that DS solution afforded a higher cerebral perfusion pressure than mannitol. The disadvantages of mannitol include decreases in blood pressure and in arterial $\mathrm{pO}_{2}$ increases in $\mathrm{pCO}_{2}$ and systemic acidosis (32). Decreases in blood $\mathrm{pH}$ after the administration of DS solution were considered less serious than the acidosis that occurred after mannitol injection. Although DS solution affects intracranial pressure in almost the same manner as mannitol under experimental conditions, the difference in tissue dehydration suggests that different mechanisms mediate their effects on intracranial pressure. Mannitol increases water content in brain tissue in the injured hemisphere, whereas DS increases water content in the tissue in the contralateral hemisphere. In addition, experimental studies showed that hypertonic saline improved cerebral perfusion pressure better than mannitol (32) because hypertonic saline has a higher potential for increasing mean arterial blood pressure (MAP). Mannitol can accumulate in damaged brain tissue after multiple doses and exacerbate vasogenic edema. Mannitol can also cause acute renal failure, hyperkalemia, hypotension and rebound increases in intracranial pressure. Berger et al. (4) reported that DS decreased the syndrome of increased intracranial pressure as effectively as mannitol in an experimental model. Bouma et al. (6) compared DS solution and mannitol based on brain edema and increased intracranial pressure. They reported that DS solution showed a greater decrease in brain edema in the traumatized hemisphere and better controlled intracranial pressure than mannitol injection. 
Mannitol showed a greater increase in serum $\mathrm{Na}^{+}$levels in an experimental model of head trauma than hypertonic DS. In addition, hypertonic DS produced a greater increase in the urine sodium concentration than mannitol (4).

Acute brain damage leads to increased levels of excitotoxic amino acids, such as glutamate, which increases the amount of reactive oxygen. Antioxidant treatment theoretically prevents progression of tissue damage, promotes increased length of life and neurological improvement. Reduced levels of GSH with GSSG formation after TBI are associated with apoptotic neuron death. A reduced rate of GSH/GSSG after trauma is an indicator of oxidative and/or nitrosative load in the system. Defense can collapse after a period of time with depletion of endogenous antioxidants. Significant increases in GSH levels were observed in the albumin, mannitol, $\mathrm{NaCl} 3 \%$ and glycerin treatment groups, which suggests that these hyperoncotic/ hyperosmotic agents protected brain tissue from the oxidative or nitrosative load that increases after trauma.

Among the secondary injuries that follow head trauma are the oxidative outcomes resulting from the substantial increase in the production of free oxygen radicals, which includes the peroxidation of lipids in cell membrane. Lipid peroxidation is the primary mechanism that triggers the conversion of unsaturated fatty acids into a radical. This process can be assessed by the measuring the formation of MDA, a substance that reacts with thiobarbituric acid. MDA levels revealed a decreasing trend in the albumin, mannitol, $3 \% \mathrm{NaCl}$ and glycerin treatment groups that indicated the cerebroventricular administration of hyperoncotic/hyperosmotic agents protected brain tissue against free oxygen radicals.

Although several antioxidant substances were effective in animal models and small clinical trials, these findings have not been confirmed in controlled or large studies. However, there are several reasons for reporting positive and negative treatment results together. One of these reasons is the infeasibility of the administration of the antioxidant substance during the period between time of the primary injury and time at which irreversible neuronal damage occurs. Another reason is the requirement for antioxidants to cross the blood-brain barrier to reach an effective dose in the central nervous system. In our study, we overcame the mechanical limitations of the bloodbrain barrier using the suggested method. Other factors that may prevent successful antioxidant treatments in the central nervous system, aside from this mechanical barrier, include short treatment intervals, inadequate dose administration, a limited dose reaching the targeted area, inconsistency in drug mechanisms and concomitant pathophysiological processes. A better understanding of the pathological mechanisms of traumatic brain injury will help establish precise targets for drug administration. The success of advanced antioxidant theory depends on defining specific noxious free radicals, adequate access to target tissue, a well-established dose and time intervals $(12,14,15,22,34)$.

In TBI, NO reacts with superoxide radicals to form peroxynitrite (ONOO-s), a highly reactive nitrating species that causes nitration of amino acid aromatic rings, lipid peroxidation, and deoxyribonucleic acid (DNA) fragmentation, all of which are fatal cellular processes $(9,16,35,36)$. In our TBI study, the decreased NO levels observed in some treatment groups suggest that cerebroventricular administration of hyperoncotic/ hyperosmotic agents protected the brain tissue from oxidative stress. In particular, cerebroventricular treatment with $\mathrm{NaCl}$ $3 \%$ produced this result, and it appears to be a promising treatment.

Inflammatory events occur within hours in patients exposed to trauma and are acute physiological responses to tissue damage, ischemia or hemorrhage. A chain of events that include the synthesis and complex interactions of cytokines and other endogenous mediators are a part of the natural recovery process. IL-1, IL-6 and TNF-a play primary roles in the inflammatory responses secondary to trauma (26). The biggest factor for acute inflammation is the vascular response in the injured area. Cytokines such as IL-1 $1 \beta$, IL- 6 are called proinflammatory cytokines and are involved in inflammatory changes and rapid immune responses that enable the elimination of pathogens. IL- 6 is the principal inducer of the acute phase response and together with IL-1 and TNF-a, it plays an important role as a fever-producing endogenous pyrogen. Its circulating levels increase after gram-negative bacterial infections and inflammatory reactions (31). The deleterious effects of interleukin-1 (IL-1) are mediated through the IL-1 receptor (IL-1R), which is expressed on microglia in focal injury, and on neurons and astrocytes in diffuse injury, where reactive astrocytosis is known to evolve early posttrauma $(8,24)$. Injury resulting from $\mathrm{IL}-1$ is not a result of the cytokine itself but rather from its propensity to activate and act synergistically with other pro-inflammatory factors, including TNF-a, cyclooxygenase-2, phospholipase A2 and prostaglandins. Furthermore, IL-1 exacerbates glutamatemediated excitotoxicity.

Although IL-1 remains a predominantly pro-inflammatory and neurotoxic molecule in TBI, it does possess certain neuroprotective characteristics, such as stimulation of neuron growth factors in astrocytes (38). As previous studies have shown, the perpetuation of neuroinflammation by IL-1 correlates with a poor prognosis. TBI patients who have elevated cerebrospinal fluid levels of IL-1 had a poorer GCS (39). Similar to IL-1, TNF-a was regarded as a purely proinflammatory cytokine in TBI studies; however, its potential neuroprotective properties have been recognized in recent years. TNF-a is known for its ability to increase the production and hypertrophy of microglia and initiate paracrine release from these cells. Diffuse injury models have shown increased serum levels of TNF-a within 24 hours of injury, but with the absence of expression in brain tissue (20). This result lends credence to the argument that diffuse injury elicits a very different immune response, including the recruitment of leukocytes from the peripheral circulation, the release of proteolytic enzymes leading to degradation of the blood-brain barrier, and inhibition of astrocytic re-population and neuronal regeneration (40).

Cytokines, NO, free oxygen radicals, and other agents with similar properties can affect neuronal and glial development. II-1 shows neuroprotective effects in low 
concentrations. Cytokine levels significantly increased in rats showing neurodegeneration in their cortices under excess production compared with control groups. Cytokine levels in blood also increased in association with cytokine levels measured in the cortex $(37,43)$. Arand et al. (2) examined posttraumatic serum levels of TNF-a, IL-1, IL-6, IL-8, IL-12 in 72 consecutive patients with multiple trauma and 22 patients with isolated head trauma, and they did not detect levels of TNF-a, IL-1, IL-8 high in any period of trauma.

In our study, TNF-a showed a tendency to increase in all treatment groups, whereas IL-1 remained low in all treatment groups. This result confirms that inflammatory cytokines are involved in acute and chronic inflammatory processes of tissue injury and elicit different immune responses.

\section{- CONCLUSION}

TBI treatment with physiologically compatible substances is crucial in maintaining a balance within an organism. Therefore, we used physiologically compatible substances suitable for use in various indications in the organism. The most important treatment advantage of intracisternal, intrathecal or intracerebroventricular route is ensuring that the agent can cross the blood-brain barrier as other treatment options cannot. The established anti-oxidant effects and the protective effects of the hyperoncotic/hyperosmotic agents on brain tissue can lead to additional support or options for current treatment methods. These results will provide insight for future studies examining treatments with larger groups and appropriate dose-time intervals.

\section{- REFERENCES}

1. Aarabi B, Long DM: Dynamics of cerebral edema. The role of an intact vascular bed in the production and propagation of vasogenic brain edema. J Neurosurg 51:779-784, 1979

2. Arand M, Melzner H, Kinzl L, Brückner UB, Gebhard F: Early inflammatory mediator response following isolated traumatic brain injury and other major trauma in humans. Langenbecks Arch Surg 386: 241-248, 2001

3. Barie PS, Ghajar JB, Firlik AD, Chang VA, Hariri RJ: Contribution of increased cerebral blood volume to postraumatic intracranial hypertension. J Trauma Acute Care Surg 35:88-95, 1993

4. Berger S, Schürer L, Hartl R, Messmer K, Baethmann A: Reduction of post-traumatic intracranial hypertension by hypertonic/hyperoncotic saline/dextran and hypertonic mannitol. Neurosurgery 37: 98-107; discussion 107-108, 1995

5. Betz AL, Coester HC: Effect of steroid therapy on ischaemic brain edema and blood to brain sodium transport. Acta Neurochir Suppl (Wien) 51: 256-258, 1990

6. Bouma GJ, Muizelaar JP, Stringer WA, Choi SC, Fatouros P, Young HF: Ultra-early evaluation of regional blood flow in severely head injuried patients using xenon-enhanced computerized tomography. J Neurosurg 77: 360-368, 1992

7. Bullock R, Chesnut RM, Clifton G, Ghajar J, Marion DW, Narayan RK, Newell DW, Pitts LH, Rosner MJ, Wilberger JW: Guidelines for the management of severe head injury. Brain Trauma Foundation. Eur J Emerg Med 3: 109-127, 1996
8. Csuka E, Hans VH, Ammann E, Trentz O, Kossmann T, Morganti-Kossmann MC: Cell activation and inflammatory response following traumatic axonal injury in the rat. Neuroreport 11: 2587-2590, 2000

9. Dawson VL, Dawson TM: Deadly conversations: Nuclearmitochondrial cross-talk. J Bioenerg Biomembr 36: 287-294, 2004

10. Duhaime AC: Conventional drug therapies for head injury. In: Narayan RK, Wilberger JE Jr, Povlishock JT (eds), Neurotrauma. New York:McGraw Hill Companies, 1996: 365374

11. Feeney DM, Boyeson MG, Linn RT, Murray HM, Dail WG: Responses to cortical injury: I. Methodology and local effects of contusions in the rat. Brain Res 211: 67-77, 1981

12. Forsythe JA, Jiang BH, lyer NV, Agani F, Leung SW, Koos RD, Semenza GL: Activation of vascular endothelial growth factor gene transcription by hypoxia-inducible factor 1 . Mol Cell Biol 16: 4604-4613, 1996

13. Greenberg MS: Head trauma. Treatment measures for elevated ICP. In: Greenberg MS (ed), Handbook of Neurosurgery, 7th ed. New York: Thieme, 2010:876-885

14. Gilgun-Sherki Y, Melamed E, Offen D: Oxidative stress inducedneurodegenerative diseases: The need for antioxidants that penetrate the blood brain barrier. Neuropharmacology 40: 959-975, 2001

15. Gilgun-Sherki Y, Rosenbaum Z, Melamed E, Offen D: Antioxidant therapy in acute central nervous system injury: Current state. Pharmacol Rev 54: 271-284, 2002

16. Halliwell B, Zhao K, Whiteman M: Nitric oxide and peroxynitrite. The ugly, the uglier and the not so good: A personal view of recent controversies. Free Radic Res 31: 651-669, 1999

17. Hariri RJ: Cerebral edema. Neurosurg Clin N Am 5: 687-706, 1994

18. Hartwell RC, Sutton LN: Mannitol, intracranial pressure, and vasogenic edema. Neurosurgery 32: 444-450; discussion 450, 1993

19. Jess FK, David LM, Terry AS, Madhangi J: Epidemiology of brain injury, In: Narayan RK, Wilberger JE Jr, Povlishock JT (eds), Neurotrauma. New York: McGraw Hill Companies, 1996:13- 30

20. Kamm K, Vanderkolk W, Lawrence C, Jonker M, Davis AT: The effect of traumatic brain injury upon the concentration and expression of interleukin-1 beta and interleukin-10 in the rat. $J$ Trauma 60: 152-157, 2006

21. Kaufnann AM, Cardoso ER: Aggravation of vasogenic cerebral edema by multiple-dose mannitol. J Neurosurg 77: 584-589, 1992

22. Kaur C, Ling EA: Blood brain barrier in hypoxic-ischemic conditions. Curr Neurovasc Res 5:71-81, 2008

23. Klatzo I: Pathophysiology of brain edema: Pathological aspects. In: Schürmann K, Brock M, Reulen HJ, Voth D (eds), Advances in Neurosurgery 1, Brain Edema, Pathophysiology and Therapy. Berlin: Springer Verlag, 1973:1-4

24. Lu KT, Wang YW, Yang JT, Yang YL, Chen HI: Effect of interleukin-1 on traumatic brain injury-induced damage to hippocampal neurons. J Neurotrauma 22: 885-895, 2005 
25. Matsui T, Sinyama $H$, Asano T: Beneficial effect of prolonged administration of albumin on ischemic cerebral edema and infarction after occlusion of middle cerebral artery in rats. Neurosurgery 33: 293-300; comment 300, 1993

26. Mayhan WG: VEGF increases permeability of the blood-brain barrier via a nitric oxide synthase/cGMP-dependent pathway. Am J Physiol 276: 1148-1153, 1999

27. Meyer FB, Anderson RE, Sundt TM Jr, Yaksh TL: Treatment of experimental focal cerebral ischemia with mannitol. Assessment by intracellular brain $\mathrm{pH}$, cortical blood flow, and electroencephalography. J Neurosurg 66: 109-115, 1987

28. Miller JD, Butterworth JF, Gudeman SK, Faulkner JE, Choi SC, Selhorst JB, Harbison JW, Lutz HA, Young HF, Becker DP: Further experience in the management of severe head injury. $J$ Neurosurg 54: 289-299, 1981

29. Olanow CW: A radical hypothesis for neurodegeneration. Trends Neurosci 16: 439-444, 1993

30. Onal C, Unal F, Turantan MI, Uzum G, Hasanoglu A, Kaynar MY: The effect of intraventricular albumin in experimental brain oedema. Acta Neurochir (Wien) 139: 661-668; discussion 668-669, 1997

31. Opal SM, DePalo VA: Anti-inflammatory cytokines. Chest 117: 1162-1172, 2000

32. Ozben T: Pathophysiology of cerebral ischemia. Mechanisms involved in neuronal damage. In: Ozben T (ed), Free Radicals, Oxidative Stress, and Antioxidants. New York: Plenum Press, 1988:163-187

33. Pappius HM: Cerebral edema and the blood-brain barrier. In: Neuwelt EA (ed), Implications of the Blood-Brain Barrier and Its Manipulation. Vol 1, Basic Science Aspects. New York: Plenum Medical Book Co, 1989: 293-309
34. Park E, Bell JD, Siddiq IP, Baker AJ: An analysis of regional microvascular loss and recovery following two grades of fluid percussion trauma: A role for hypoxia-inducible factors in traumatic brain injury. J Cereb Blood Flow Metab 29: 575-584, 2009

35. Pellegrino LJ, Pellegrino AS, Cushman AJ: A stereotactic atlas of the rat brain. New York: Plenum Pres, 1979

36. Radi R, Beckman JS, Bush KM, Freeman BA: Peroxynitriteinduced membrane lipid peroxidation: The cytotoxic potential of superoxide and nitric oxide. Arch Biochem Biophys 288: 481-487, 1991

37. Rothwell NJ, Strijbos PJ: Cytokines in neurodegeneration and repair. Int J Dev Neurosci 13: 179-185, 1995

38. Rothwell N: Interleukin-1 and neuronal injury: Mechanisms, modification, and therapeutic potential. Brain Behav Immun 17: 152-157, 2003

39. Shiozaki T, Hayakata T, Tasaki O, Hosotubo H, Fuijita K, Mouri T, Tajima G, Kajino K, Nakae H, Tanaka H, Shimazu $\mathrm{T}$, Sugimoto $\mathrm{H}$ : Cerebrospinal fluid concentrations of antiinflammatory mediators in early-phase severe traumatic brain injury. Shock 23: 406-410, 2005

40. Shohami E, Ginis I, Hallenbeck JM: Dual role of tumor necrosis factor alpha in brain injury. Cytokine Growth Factor Rev 10: 119-130, 1999

41. Stratford N: Antioxidant potential of i.v. fluids. Br J Anaesth 78: 757-759, 1997

42. Unterberg AW, Stover J, Kress B, Kiening KL: Edema and brain trauma. Neuroscience 129:1021-1029, 2004

43. ZhuT, Yao Z, Yuan HN, Lu BG, Yang SY: Changes of interleukin-1 beta, tumor necrosis factor alpha and interleukin- 6 in brain and plasma after brain injury in rats. Chin $\mathrm{J}$ Traumatol 7: 3235,2004 